\title{
Laser Velocimeter Measurements in the Pump of an Automotive Torque Converter Part II - Effect of Pump Speed and Oil Viscosity
}

\author{
RONALD D. FLACK*, STEVEN B. AINLEY, KLAUS BRUN and LEONARD WHITEHEAD \\ Department of Mechanical, Aerospace, and Nuclear Engineering, University of Virginia, \\ Charlottesville, VA 22903-2442, USA
}

(Received 30 June 1997; In final form 31 July 1998)

\begin{abstract}
The velocity field inside a torque converter pump was studied for two separate effects: variable pump rotational speed and variable oil viscosity. Three-dimensional velocity measurements were taken using a laser velocimeter for both the pump mid- and exit planes. The effect of variable pump rotational speed was studied by running the pump at two different speeds and holding speed ratio (pump rotational speed/turbine rotational speed) constant. Similarly, the effect of viscosity on the pump flow field was studied by varying the temperature and/or using two different viscosity oils as the working fluid in the pump. Threedimensional velocity vector plots, through-flow contour plots, and secondary flow profiles were obtained for both pump planes and all test conditions. Results showed that torque converter mass flows increased approximately linearly with increasing pump rotational speed (and fixed speed ratio) but that the flow was not directly proportional to pump rotational speed. However, mass flows were seen to decrease as the oil viscosity was decreased with a resulting increased Reynolds number; for these conditions the high velocity regions were seen to decrease in size and low velocity regions were seen to increase in size. In the pump mid-plane strong counter-clockwise secondary flows and in the exit plane strong clockwise secondary flows were observed. The vorticities and slip factors were calculated from the experimental results and are presented. The torque core-to-shell and blade-to-blade torque distributions were calculated for both planes. Finally, the flow fields were seen to demonstrate similitude when Reynolds numbers were matched.
\end{abstract}

Keywords: Torque converters, Pumps, Laser velocimetry

\section{INTRODUCTION}

The torque converter is a single stage, hydrodynamic turbomachine with two rotating components and one stationary component and are commonly used in automobiles with automatic transmissions. The automotive torque converter function and application is described in detail in Part I of this paper (Ainley et al., 1998).

*Corresponding author. Tel.: (804) 924 6213. Fax: (804) 982 2037. E-mail: rdf@ ,virginia.edu. 


\section{Previous Torque Converter Internal Flow Studies}

Previous torque converter studies were reviewed in Part I of this paper and are not presented here for the sake of brevity. Static and dynamic pressure measurements were taken in the stator, pump and turbine of the torque converter by By and Lakshminarayana (1995), By et al. (1995), Marathe et al. (1996), and Marathe and Lakshminarayana (1995). Laser velocimeter measurements were taken by Bahr et al. (1990), Gruver et al. (1996), Brun et al. (1996) and Ainley et al. (1998). In all of the above the flow fields were found to be highly threedimensional and strong secondary flows were found.

Ainley et al. (1998) used the same apparatus as Bahr et al. (1990) and Gruver et al. (1996) to measure velocities in the pump of the torque converter. In the mid- and exit planes of the pump, the effect of various speed ratios $(0.200,0.400,0.600$ and 0.800 ) with a constant pump rotational speed was studied. A laser velocimeter was used to measure three components of velocity within the pump mid- and exit planes. Mass flows for both planes at all four speed ratios were calculated from the velocity data and were found to decrease as the speed ratio was increased. The mid-plane was found to have strong counter-clockwise secondary flows and the exit plane was found to have strong clockwise secondary flows for all conditions. The vorticity and slip factors were calculated from the data and are presented.

\section{Research Objectives}

Two separate effects on the torque converter pump mid- and exit plane flow fields were studied. For the pump rotational speed effect study, the speed ratio was held constant at 0.800 and the pump was run at three different rotational speeds $(1100,550$ and $314 \mathrm{rpm}$ ). Three-dimensional velocity profiles, secondary flows, and through-flow contour plots are presented in this paper and discussed. For the oil viscosity effect study, the nominal working oil was replaced with a lower viscosity oil and heated to 3 different temperatures in order to vary the viscosity. Speed ratios of 0.065 and 0.800 were studied in both the mid- and exit planes for this part of the study. Through-flow velocity plots for the second part of the study are presented and discussed. Mass flows for all cases studied were calculated and are presented. Vorticity, slip factors, and torque flux distributions were calculated from the velocity data and are also presented and discussed.

\section{EXPERIMENTAL FACILITY}

The torque converter rig and laser velocimeter (LV) system were described in detail in Part I of this paper (Ainley et al., 1998). Shellflex 212 oil was used as the working fluid for the study of the effect of the pump rotational speed. Diala oil was used as the working fluid for the study of the effect of the varying the oil viscosity.

Each blade passage was defined by a pressure, suction, core and shell side as shown in Fig. 1. For each pump plane a measurement grid of 9 core-toshell by 37 blade-to-blade relative positions was resolved as described by Ainley et al. (1998). Approximately 135 valid velocity samples were collected for each measurement grid position in the rotating frame, which is sufficient for a high

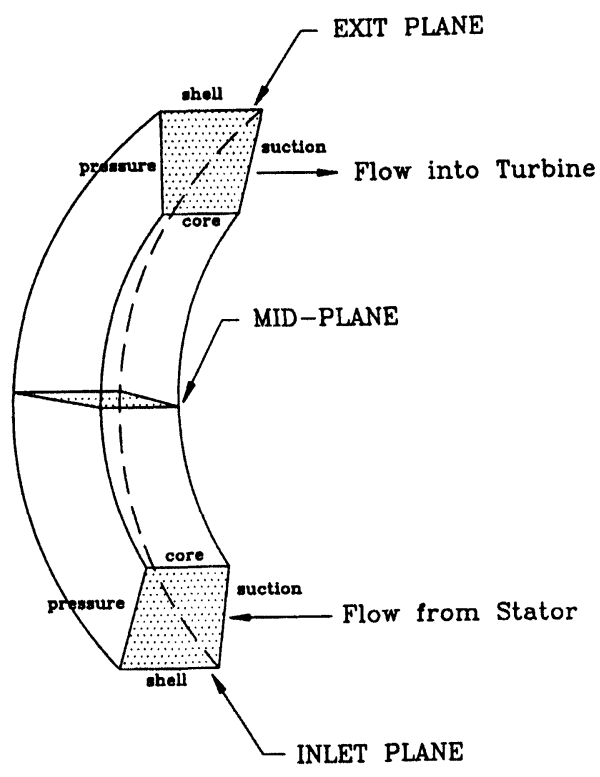

FIGURE 1 Pump passage geometry. 
TABLE I Test Conditions

\begin{tabular}{|c|c|c|c|c|c|c|c|}
\hline$N_{\mathrm{t}}(\mathrm{rpm})$ & $N_{\mathrm{p}}(\mathrm{rpm})$ & Oil Type & Speed Ratio & Temp. $\left({ }^{\circ} \mathrm{C}\right)$ & $\nu(\mathrm{cSt})$ & $\operatorname{Re}($ tip speed) & Re (through flow) \\
\hline 880 & 1100 & Shellflex & 0.800 & 30 & 24.8 & 10100 & 1150 \\
\hline 440 & 550 & Shellflex & 0.800 & 25 & 28.2 & 4500 & 400 \\
\hline 251 & 314 & Shellflex & 0.800 & 23 & 29.7 & 2400 & 200 \\
\hline 52 & 800 & Shellflex & 0.065 & 40 & 19.0 & 9600 & 2180 \\
\hline 880 & 1100 & Diala & 0.800 & 25 & 19.0 & 13200 & 1650 \\
\hline 880 & 1100 & Diala & 0.800 & 40 & 9.7 & 26000 & 2600 \\
\hline 880 & 1100 & Diala & 0.800 & 50 & 5.5 & 42000 & 3900 \\
\hline 52 & 800 & Diala & 0.065 & 25 & 19.0 & 9600 & 2250 \\
\hline 52 & 800 & Diala & 0.065 & 40 & 9.7 & 18900 & 3900 \\
\hline 52 & 800 & Diala & 0.065 & 50 & 5.5 & 30500 & 5500 \\
\hline
\end{tabular}

confidence in the average velocities. The instantaneous angular positions of the pump and turbine were recorded for each valid velocity signal from the shaft encoders on both the pump and turbine shafts.

Table I indicates the operating conditions of the torque converter for the cases studied. For all cases, the stator does not rotate. The entire experimental facility and data acquisition procedure were described by Bahr et al. (1990), Gruver et al. (1996), and Ainley et al. (1997) and the detailed dimensions of the torque converter and passage geometries were given by By and Lakshminarayana (1995).

For reference, the Reynolds numbers were calculated for the exit plane for all the operating conditions and are included in Table I. The Reynolds number, $\operatorname{Re}=V D_{\mathrm{h}} / \nu$, was calculated in two ways: (i) based on the through-flow velocity and (ii) based on the pump tip speed. For both methods of calculation, the hydraulic diameter, $D_{\mathrm{h}}$, equals $4 A / P$, where $A$ is the area of the measurement plane and $P$ is the wetted perimeter. The hydraulic diameter was $0.01901 \mathrm{~m}$ in the pump exit plane. For the Reynolds number calculation based on the through-flow, $V$ is simply the average through-flow velocity in that plane, and for the calculation based on the tip speed, $V$ is the velocity of the tip of the pump blade $(V=r \omega)$.

\section{RESULTS AND DISCUSSION}

As previously described, experimental data was obtained for two pump planes at ten different test conditions. The first three test conditions were used to determine the effect of varying the pump speed while holding the speed ratio constant and thus to complement the data of Gruver et al. (1996). The remaining conditions were used to determine the effect of varying the oil viscosity and thus Reynolds number on the pump flow field; for these tests two different oils were utilized. All velocities shown herein are relative to the rotating pump frame. Mass flows, slip factors, and vorticities were calculated from the average velocity data. Torque fluxes are derived from the angular momentum fluxes and slip factors are determined from the relative tangential velocities.

\section{Effect of Pump Rotational Speed}

Mass flux The mass flows were calculated for the mid- and exit planes from the experimental data by integrating the through-flow velocity multiplied by the area and density across the entire measurement plane. The small differences between the mass flows from the mid-plane to the exit plane are well within the calculated mass flow uncertainties. The measured mass flow rate for the two planes and three speeds are shown in Fig. 2 for the speed ratio of 0.800 and Shellflex oil. The mass flow rate increases as the pump speed is increased. Although the increase is approximately linear with rotational speed, the mass flow rate is not proportional to rotational speed. Also presented in Fig. 2 are results for Diala oil at a pump speed of $1100 \mathrm{rpm}$ and at approximately the same 


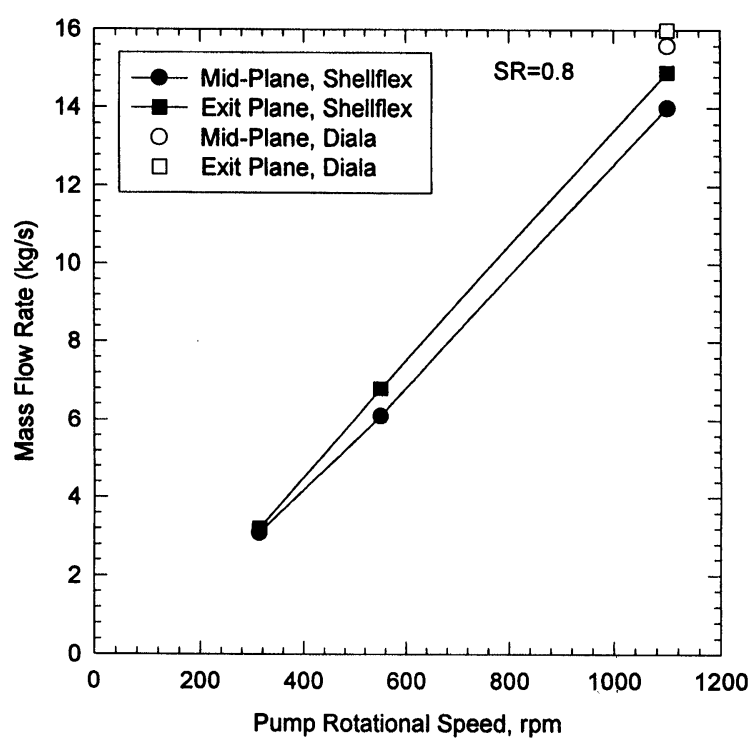

FIGURE 2 Pump mass flow rate as a function of pump rotational speed.

Reynolds number (13 200). Results are in approximate agreement with the Shellflex oil results, indicating similitude.

To identify mass flux distributions for $\mathrm{SR}=0.800$ Figs. 3 and 4 are presented for two pump rotational speeds. Figure 3 shows the mass flux distribution from pressure-to-suction (bladeto-blade) for both planes at speeds of 314 and $550 \mathrm{rpm}$. For this figure the mass flux was averaged from core to shell. For both planes, the highest mass flux is located at $10-20 \%$ of the pressure-to-suction surface. Near the suction side of the blade passage the mass flow is minimal and actually negative for high speed ratios in the mid-plane, indicating reverse flow. The core-to-shell mass flux distribution for both the mid- and exit planes at the same speeds is shown in Fig. 4. For this figure the mass flux was averaged from pressure to suction surface. Near the core side of the blade passage the mass flux is nearly zero in both the mid- and exit planes; the mass flux increases steadily towards the shell side of the passage in both planes. The general observation from both Figs. 3 and 4 is that for all cases and planes, the magnitudes of the mass flux increase as

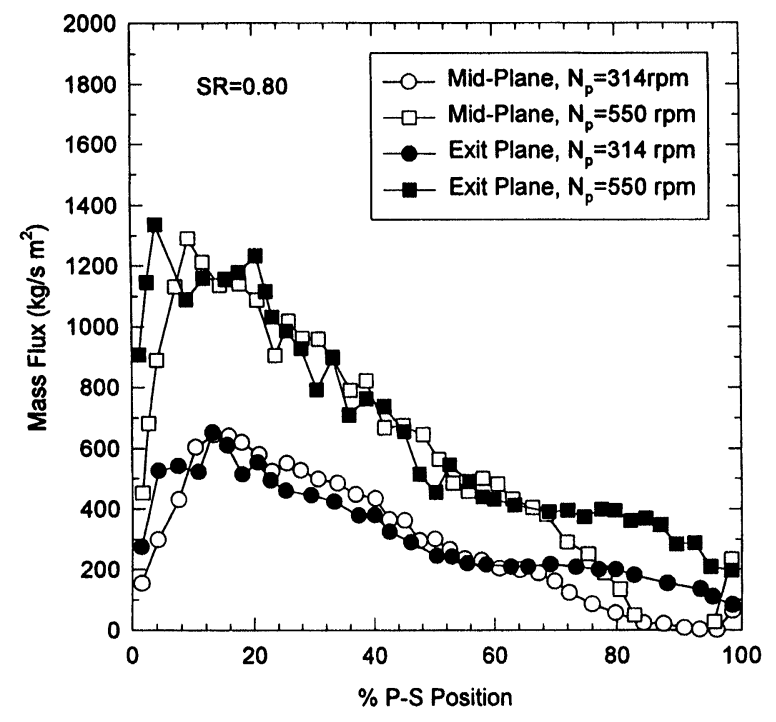

FIGURE 3 Pressure-to-suction surface mass flux distribution for pump speeds 314 and $550 \mathrm{rpm}$.

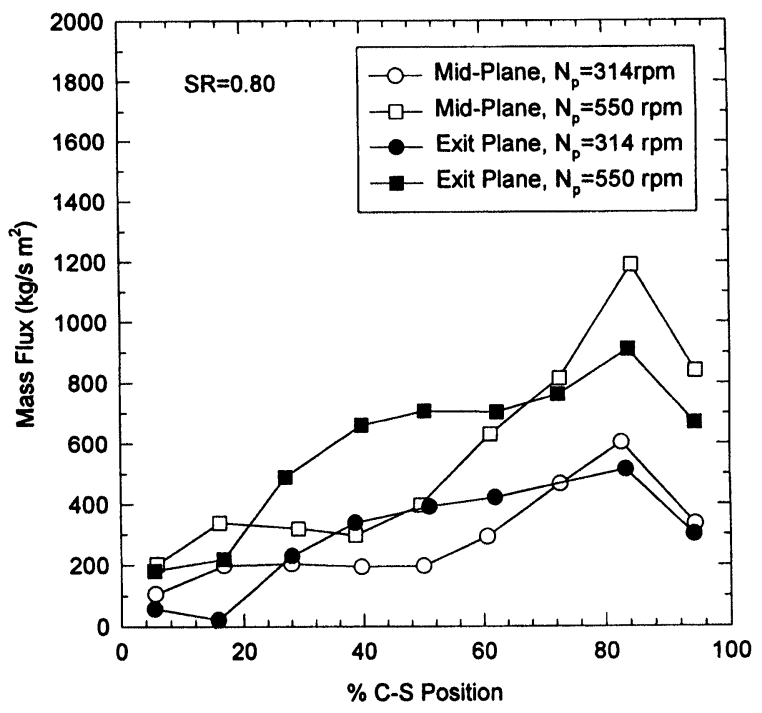

FIGURE 4 Core-to-shell surface mass flux distribution for pump speeds 314 and $550 \mathrm{rpm}$.

the speed increases and that the general shapes of the distribution are approximately independent of speed.

Torque flux distribution The torque flux distribution was calculated for each differential from 
the following:

$$
\text { Torque Flux }=\vec{r}_{i} \vec{V}_{\theta_{i}} \rho \vec{V}_{n_{i}}
$$

where $V_{\theta}$ is the absolute tangential velocity, $r_{i}$ is the radius from the shaft center, and $V_{n}$ is the through-flow velocity. The pressure-to-suction (blade-to-blade) torque flux distribution for the same two speeds as above is shown in Fig. 5 for both the mid- and exit planes and the core-to-shell torque flux distribution is shown in Fig. 6. For these two figures the torque flux was averaged from core to shell and pressure to suction surface, respectively. The highest torque is located at approximately $10-20 \%$ pressure-to-suction and $85 \%$ core-to-shell in both the mid- and exit planes, regardless of speed. Along the suction side and the core side of the blade passage, the torque flux is minimal. In the mid-plane near the suction surface the torque flux is negative for the high speed. Low torque flux regions indicate areas where minimal beneficial pump work is being done on the fluid. The magnitudes of the torque flux increase as the speed increases, as expected when considering the mass flux distribution. The

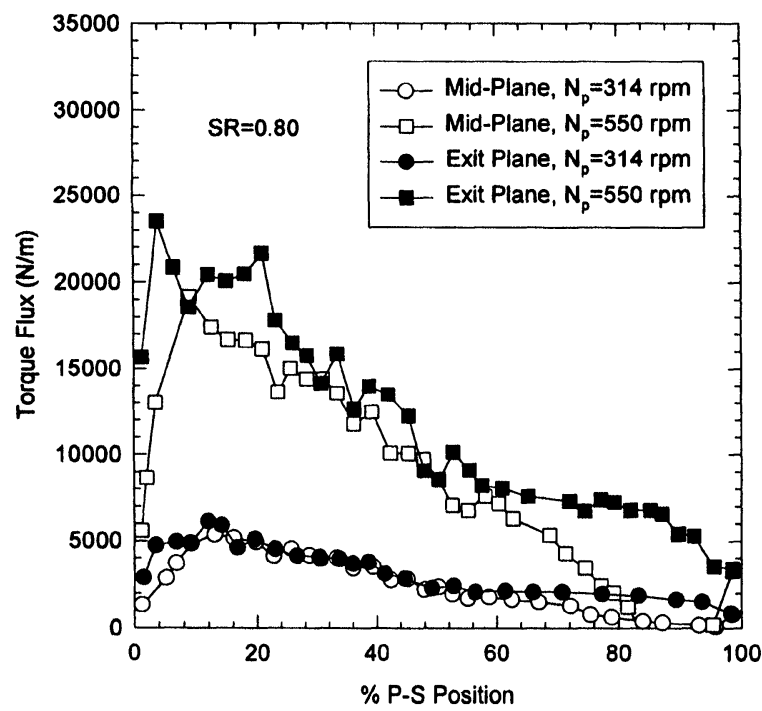

FIGURE 5 Pressure-to-suction surface torque flux distribution for pump speeds 314 and $550 \mathrm{rpm}$. general observation from both Figs. 5 and 6 is that for all cases and planes, the magnitudes of the torque flux increase as the speed increases and that the general shapes of the distribution are approximately independent of speed.

Vorticity The average flow vorticity, $\xi$, is defined in the pump by the following equation:

$$
\begin{aligned}
\xi & =-\frac{1}{A} \iint(\nabla \times \vec{v}) \cdot \mathrm{d} A \\
& =-\frac{1}{A} \iint\left(\frac{\partial v}{\partial x}-\frac{\partial u}{\partial y}\right) \mathrm{d} A
\end{aligned}
$$

where $u$ is the core-to-shell velocity and $v$ is the pressure-to-suction velocity. The values of $x$ and $y$ are the absolute coordinates of the core-to-shell and pressure-to-suction locations, respectively. The vorticity, calculated from a discretized form of the above equation and the experimental data, was non-dimensionalized by dividing by the average through-flow velocity and multiplying by a reference length. The reference length for this calculation is the core-to-shell length of the pump blade $(15.5 \mathrm{~mm})$. The non-dimensional vorticity

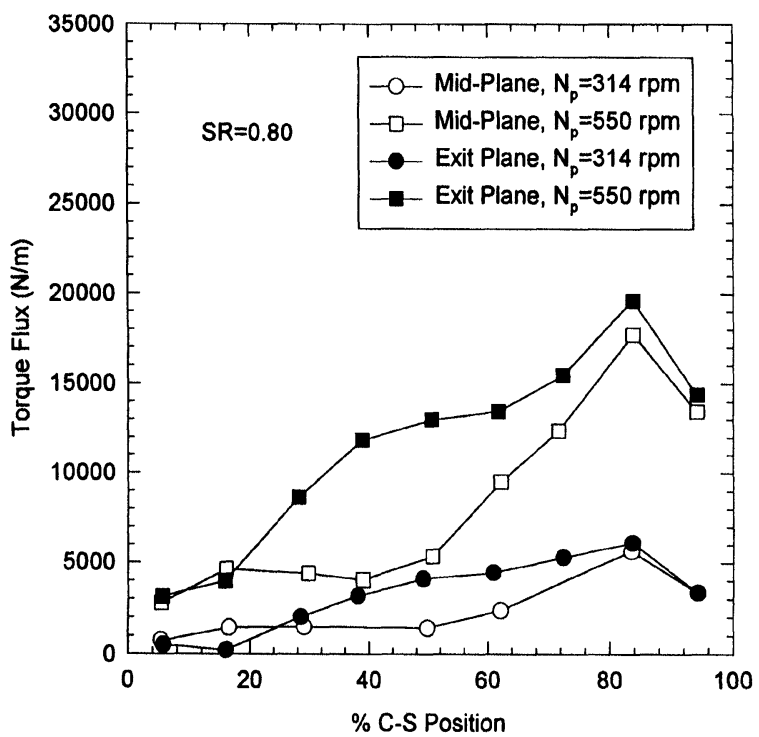

FIGURE 6 Core-to-shell surface torque flux distribution for pump speeds 314 and $550 \mathrm{rpm}$. 
values are shown in Fig. 7 for both planes at the three rotational speeds.

A positive vorticity value represents a secondary flow rotation in the counter-clockwise direction when looking directly into the plane from a downstream position. The highest mid-plane vorticity

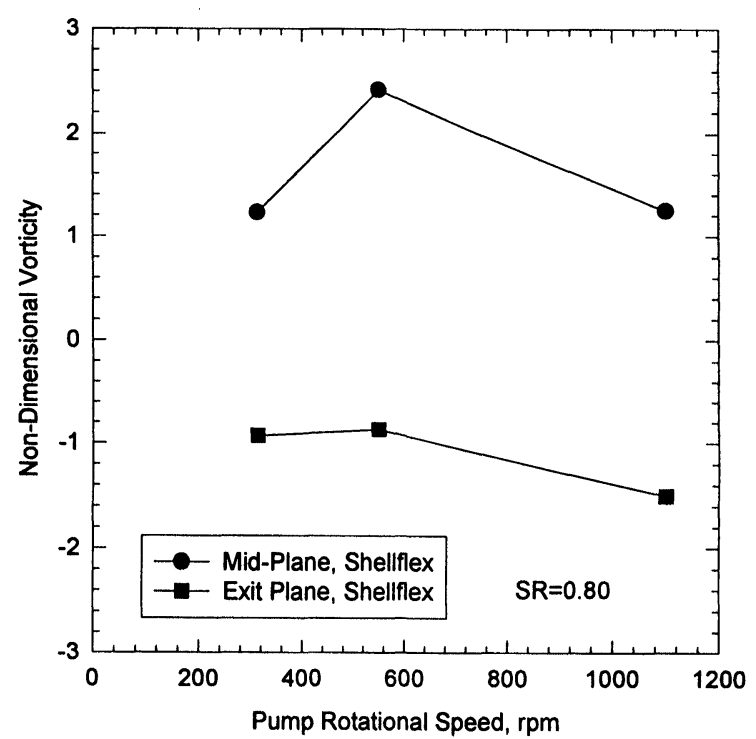

FIGURE 7 Non-dimensional vorticity as a function of pump rotational speed. occurs at a speed of $550 \mathrm{rpm}$ and the largest vorticity (negative) in the exit plane occurs at a speed $1100 \mathrm{rpm}$.

Figure 8 shows the secondary flow pattern of the mid-plane at the speed ratio of 0.800 and speed of $550 \mathrm{rpm}$. Secondary flows are the relative velocities (with respect to the pump frame) normal to the through-flow component. The secondary flows in the mid-plane have a strong counter-clockwise rotational circulation. Average secondary velocities are approximately $1.0 \mathrm{~m} / \mathrm{s}$. The region of highest velocities is located at $30 \%$ pressure-to-suction and these velocities are $1.2 \mathrm{~m} / \mathrm{s}$. Lower velocities are located in the core-suction corner region. The midplane velocity results for the other two conditions at a speed ratio of 0.800 (Shellflex oil) show similar flow trends but different overall velocity magnitudes. Such plots are not presented for the sake of brevity.

Figure 8 also shows the secondary flow pattern of the exit plane at the speed ratio of 0.800 and $5507 \mathrm{rpm}$. The secondary flows in the exit plane have a strong clock-wise rotational circulation, which is opposite that of the mid-plane. The peak secondary flows are approximately $1.2 \mathrm{~m} / \mathrm{s}$. A combined effect of the Coriolis and centrifugal forces

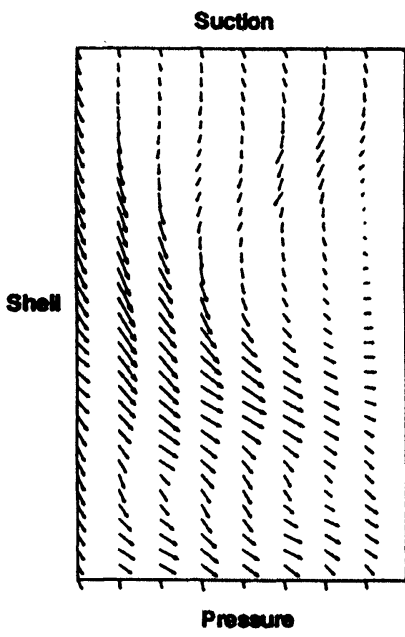

Mid-Plane
$1=1.5 \mathrm{~m} / \mathrm{s}$
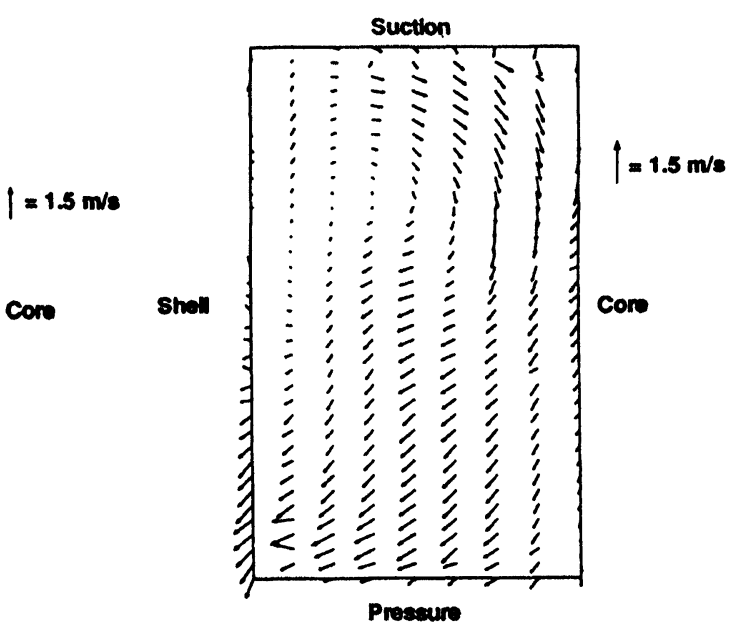

Exit Plane

FIGURE 8 Secondary flows in mid- and exit planes for $N_{\mathrm{p}}=550 \mathrm{rpm}$. 
as well as shear forces on the fluid are responsible for the strong secondary flow in both the mid- and exit planes. The exit plane velocity results for the other two test conditions again show similar flow trends but again, the magnitudes are different and, again, such plots are not presented for the sake of brevity.

Slip Factor The slip factor, $\mu$, is defined as the ratio of the actual fluid absolute tangential velocity to the ideal fluid tangential velocity. The slip factor was calculated using the equation below for all speeds and for both mid- and exit planes:

$$
\mu=\sum \frac{v_{i}+\omega r_{i}}{\omega r_{i}} \cdot \frac{w_{i}}{w_{\text {avg }}}
$$

where $v_{i}$ is the relative tangential fluid velocity, $\omega$ is the angular velocity in $\mathrm{rad} / \mathrm{sec}, r_{i}$ is the radius of the measurement point, $w_{i}$ is the through-flow velocity, and $w_{\text {avg }}$ is the average through-flow velocity. The calculated values of slip are weighted by the through-flow velocity, as seen in the above equation. The pump slip factors are shown in Fig. 9 along with the values predicted for a 27-blade conventional centrifugal pump by Stodola (1945),

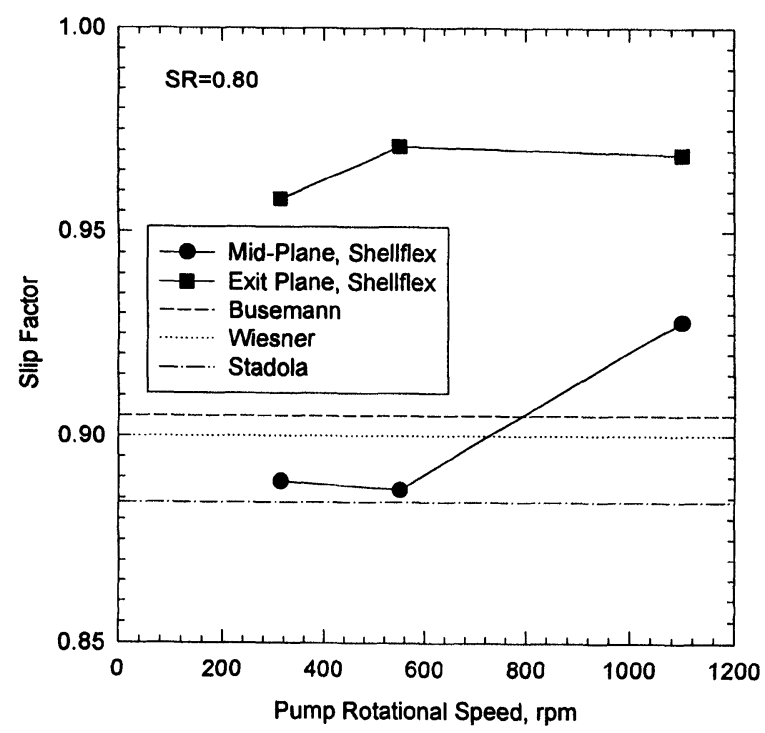

FIGURE 9 Pump slip factor as a function of pump rotational speed.
Busemann (1928), and Wiesner (1967). The slip factors varied only slightly between the speeds with a small increase with speed, but the values in the exit plane are significantly higher than in the mid plane. The mid-plane values range from 0.887 to 0.928 and the exit plane values range from 0.958 to 0.971 .

The calculated values of the slip factor from measurements at the torque converter pump midplane are similar to the predicted values based on centrifugal pump data. This small difference can be attributed to the fact that, as previously indicated, the torque converter pump operates similar to a centrifugal pump especially in the inlet to mid-plane section (the through-flow is in the radial direction). The values of the slip factor for the exit plane do not, however, agree as well with the predicted values. The measured slip factor values are significantly higher than the predicted values. The additional chord length from the mid-plane to the exit plane (nominal chord length between the inlet and exit plane is 2.2 times greater than from the inlet to the mid-plane) provides additional guidance to the flow and produces a higher slip factor (less slip) than for a normal centrifugal pump.

\section{Effect of Oil Viscosity}

Mass flow rate The mass flows were calculated for the mid-and exit planes from the experimental data again using the through-flow velocity. The small differences between the mass flows from the mid-plane to the exit plane are again well within the calculated mass flow uncertainties. The measured mass flow rate for the two planes, Diala oil, and three Reynolds numbers are shown in Fig. 10 for both speed ratios. The mass flow rate decreases as the Reynolds number is increased. Also presented in Fig. 10 are results for Shellflex oil. Results for the Shellflex oil are in agreement with the Diala oil results, indicating that similitude was achieved by the matching of Reynolds numbers.

Velocity fields The mid-plane through-flow velocities at a speed ratio of 0.800 are shown by Fig. 11 for two Reynolds numbers. In general a 


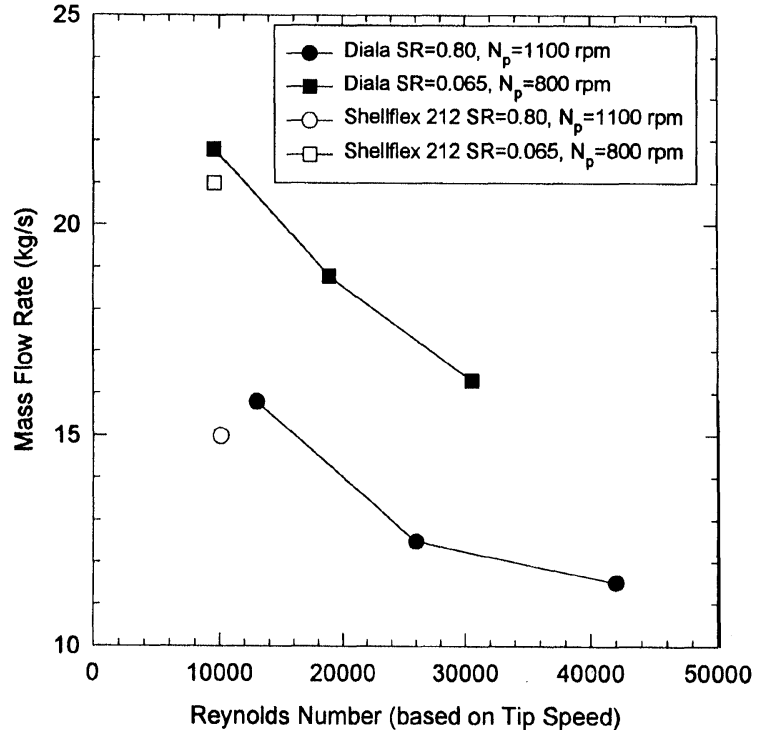

FIGURE 10 Pump mass flow rate as a function of Reynolds number.

separation region is located along the suction surface/core surface corner and velocities in this region are as low as -0.25 times the average through-flow velocity. The highest velocities $(2.2$ times the average through-flow velocity) are located in the pressure surface/shell surface corner of the passage. Figure 12 shows the exit plane through-flow velocity field at a speed ratio of 0.800 again for two Reynolds numbers. A separation region is located midway from pressure to suction along the core side of the plane. Velocities in this region reach as high as -0.25 times the average through-flow velocity. A low velocity region extends along the entire suction and core sides of the plane. Highest velocities are located along the pressure side of the passage and measure 2.2 times the average through-flow velocity.

The effect of an increasing Reynolds number is seen to increase the size of the separation region and also decrease the size of the high velocity region. In general the characteristic shape of the through flow velocity field is unaffected by the Reynolds number. As the Reynolds number increased, the diagonal line dividing the two regions moves from the
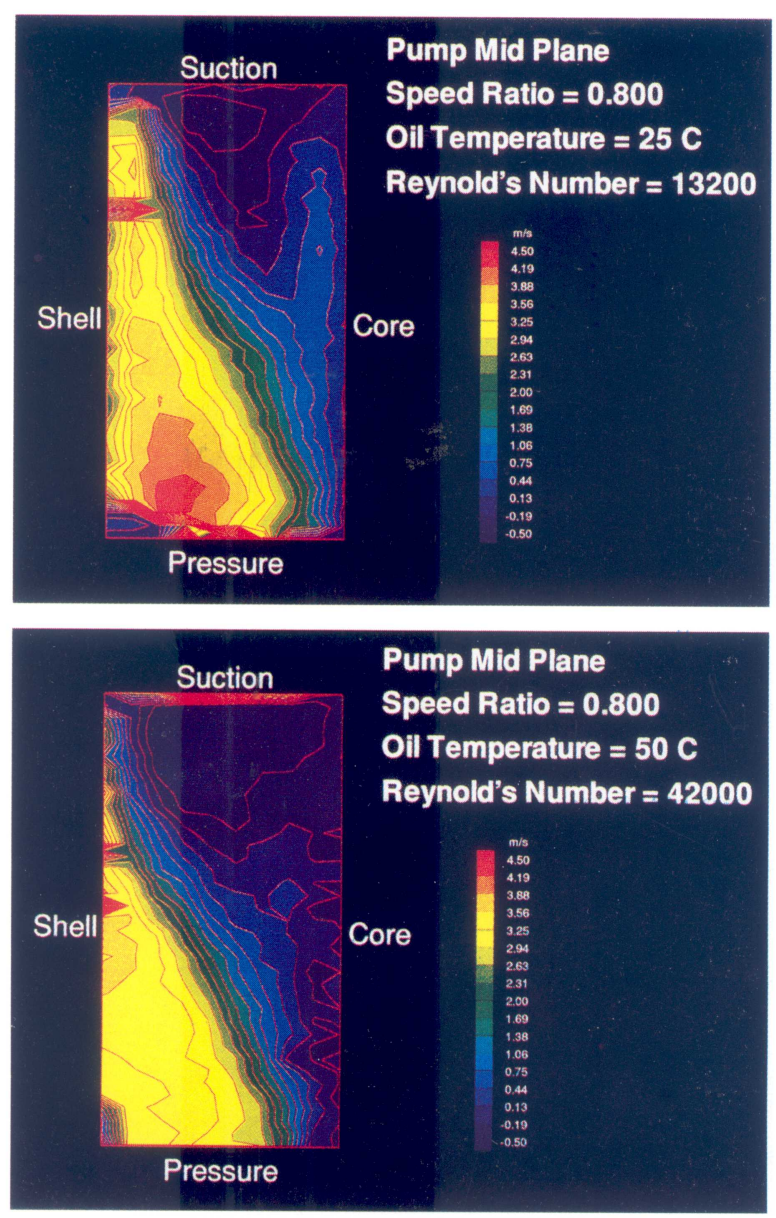

FIGURE 11 Through-flow velocity contours in mid-plane for Reynolds numbers 13200 and 42000. (See Color Plate I at the back of this issue.)

suction/core quadrant towards the pressure/shell quadrant. Thus, as Re is increased, the flow rate decreases as evidenced by Fig. 10 .

Secondary flows were relatively unaffected by changes in Reynolds number. Changes in nondimensional vorticities were within the uncertainty of the calculations.

\section{CONCLUSIONS}

A laser velocimeter was used to measure the flow field in the mid- and exit planes of an automotive torque converter pump. Ten test conditions were studied for both planes in order to determine the 

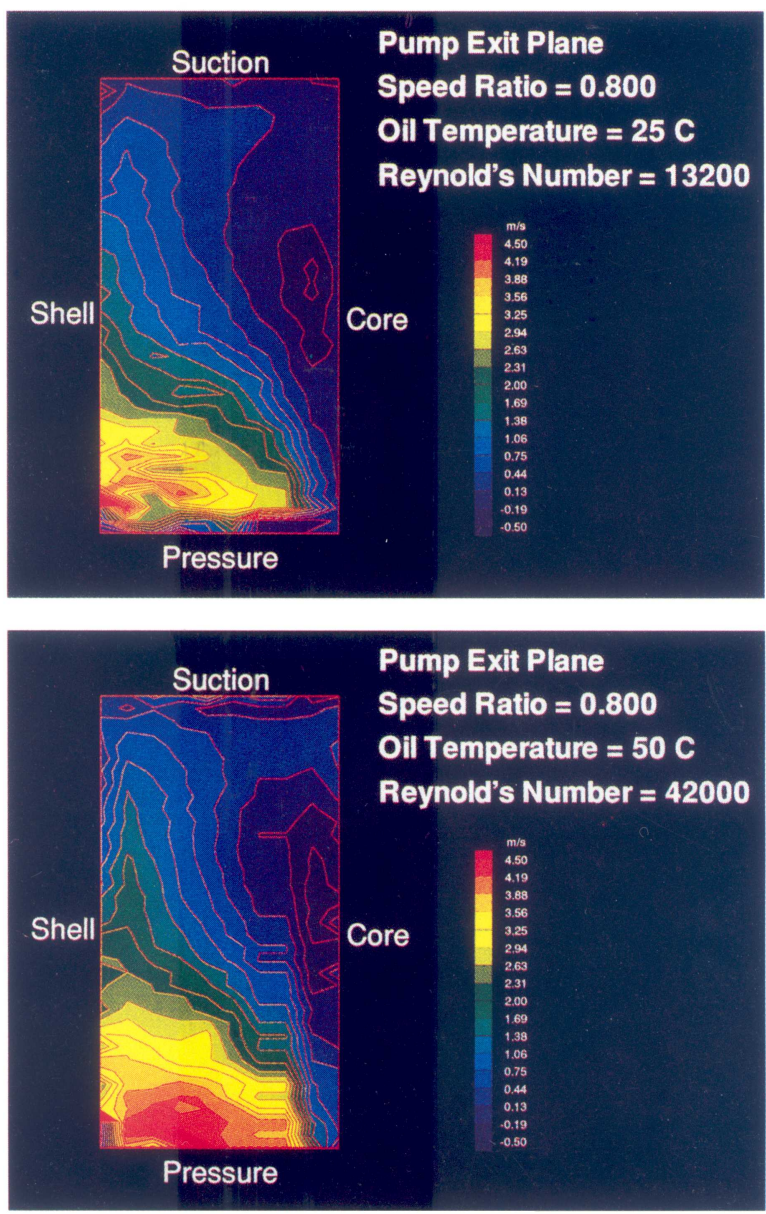

FIGURE 12 Through-flow velocity contours in exit plane for Reynolds numbers 13200 and 42000. (See Color Plate II at the back of this issue.)

effect of the pump speed and the effect of varying the oil viscosity. The conclusions drawn from this investigation are:

1. While the pump speed was increased from 314 to $1100 \mathrm{rpm}$ and the speed ratio held constant at 0.800 , the mass flows increased in the midplane from 3.1 to $14.0 \mathrm{~kg} / \mathrm{s}$ and increased in the exit plane from 3.2 to $14.9 \mathrm{~kg} / \mathrm{s}$. Although the increase was approximately linear with speed, the mass flow rate was not proportional to pump rotational speed.

2. The mass flux distributions show that the mass flux is highest near the pressure and shell side of the blade passage in both the mid- and exit planes. Separation regions at a speed ratio of 0.800 are located near the suction side of the mid-plane and the core side of the exit plane. The general mass flux distribution did not change with speed.

3. The torque flux distributions show that the torque flux is highest near the pressure and shell side of the blade passage in both the mid- and exit planes. The general distribution did not change with speed.

4. Strong secondary flow patterns are present in both the mid- and exit planes as is evident from the calculated vorticity values for the operating conditions using the Shellflex oil. The secondary flow is counter-clockwise in the mid-plane and clockwise in the exit plane. The general secondary patterns did not change with speed, although the magnitudes did change with speed. The strongest secondary flow occurs at a pump speed of $550 \mathrm{rpm}$ in the mid-plane and at $1100 \mathrm{rpm}$ in the exit plane. The circulation is the result of the combination of Coriolis, centrifugal and viscous forces.

5. The slip factors in the torque converter pump were calculated for $\mathrm{SR}=0.800$ using the Shellflex oil and compared to predicted values for conventional centritugal pumps. The calculated values at the mid-plane compared favorably with the predicted values. However, the pump exit plane slip factors were higher than predicted values. The added passage length adds to the fluid control, and thus reduces the amount of slip present at the exit plane. The slip factor increased slightly with increasing speed.

6. For the speed ratio of 0.065 (Diala oil), the mass flows decreased from 22.5 to $16.6 \mathrm{~kg} / \mathrm{s}$ and 21.0 to $16.0 \mathrm{~kg} / \mathrm{s}$ in both the mid- and exit planes, respectively, as the oil temperature was increased and the resulting Reynolds number increased from 13200 to 42000 . The mass flows at a speed ratio of 0.800 (Diala oil) decreased from 15.6 to $10.6 \mathrm{~kg} / \mathrm{s}$ and from 16.1 to $12.4 \mathrm{~kg} / \mathrm{s}$ in the midand exit planes, respectively, as the resulting Reynolds number increased from 13200 to 42000. For similar Reynolds numbers the mass 
flow rates agreed with results for Shellflex oil indicating similitude was achieved.

7. The effect of increasing the Reynolds number is seen to increase the size of the separation region and also decrease the size of the high velocity region, which is consistent with the measured flow rates. The general shape of the through flow velocity field is unaffected by the Reynolds number. As the Reynolds number increased, the diagonal line dividing the high and low velocity regions moves from the suction/core corner towards the opposite corner.

\section{Acknowledgments}

This research was sponsored by General Motors Corporation Powertrain Division. The authors wish to express their gratitude to D. Maddock for his technical and hardware support. The research was also supported in part by the Rotating Machinery and Controls Laboratory at the University of Virginia.

\section{References}

Ainley, S.B., Brun, K., Flack, R.D., Rovello, T.J. (1997) Laser velocimetry measurements in the pump of an automotive torque converter - Part I - Effect of speed ratio, International Journal of Rotating Machinery, 6(3), 167-180.

Bahr, H.M., Flack, R.D., By, R.R. and Zhang, J.J. (1990) Laser velocimetry measurement in the stator of a torque converter (SAF Paper No. 901769, SAE 1990 Transactions), Journal of Passenger Cars, 99(6), 1625-1634.

Brun, K., Flack, R.D. and Gruver, J.K. (1996) Laser velocimeter measurements in the pump of an automotive torque converter: Part II - Unsteady measurements (ASME Transactions), Journal of Turbomachinery, 118, 570-577.

Busemann, A. (1928) Das förderhöhenverhältnis radialer kreiselpumpen mit logarithmischspiraligen schaufeln, Zeitschrift für Angewandte Mathematik und Mechanik, 8, 372-384.

By, R.R. and Lakshminarayana, B. (1995) Measurement and analysis of static pressure field in a torque converter pump (ASME Transactions), Journal of Fluids Engineering, 117, $109-115$.

By, R.R., Kunz, R.F. and Lakshminarayana, B. (1995) Navier Stokes analysis of the pump of an automotive torque converter (ASME Transactions), Journal of Fliuds Engineering, 117, 116-122.

Gruver, J.K., Flack, R.D. and Brun, K. (1996) Laser velocimeter measurements in the pump of a torque converter: Part I Average measurements (ASME Transactions), Journal of Turbomachinery, 118, 562-569.

Marathe, B.V. and Lakshminarayana, B. (1995) Experimental investigation of steady and unsteady flow field downstream of an automotive torque converter turbine and stator, International Journal of Rotating Machinery, 2, 67-84.

Marathe, B.V., Lakshminarayana, B. and Dong, Y. (1996) Experimental and numerical investigation of stator exit flow field of an automotive torque converter (ASME Transactions), Journal of Turbomachinery, 118, 835-843.

Stodola, A. (1945) Steam and Gas Turbines, Peter Smith Publisher, Gloucester, Mass.

Wiesner, F.J. (1967) A Review of slip factors for centrifugal impellers (ASME Transactions), Journal of Engineering for Power, 89, 558-572. 


\section{ait \\ ENERGY MATERIALS}

M A N E Y publishing

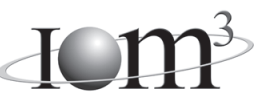

\section{Materials Science \& Engineering for Energy Systems}

Maney Publishing on behalf of the Institute of Materials, Minerals and Mining

The Institute of Materials, Minerals \& Mining

Economic and environmental factors are creating ever greater pressures for the efficient generation, transmission and use of energy. Materials developments are crucial to progress in all these areas: to innovation in design; to extending lifetime and maintenance intervals; and to successful operation in more demanding environments. Drawing together the broad community with interests in these areas, Energy Materials addresses materials needs in future energy generation, transmission, utilisation, conservation and storage. The journal covers thermal generation and gas turbines; renewable power (wind, wave, tidal, hydro, solar and geothermal); fuel cells (low and high temperature); materials issues relevant to biomass and biotechnology; nuclear power generation (fission and fusion); hydrogen generation and storage in the context of the 'hydrogen economy'; and the transmission and storage of the energy produced.

As well as publishing high-quality peer-reviewed research, Energy Materials promotes discussion of issues common to all sectors, through commissioned reviews and commentaries. The journal includes coverage of energy economics and policy, and broader social issues, since the political and legislative context influence research and investment decisions.

\section{CALL FOR PAPERS}

Contributions to the journal should be submitted online at http://ema.edmgr.com

To view the Notes for Contributors please visit: www.maney.co.uk/journals/notes/ema

Upon publication in 2006, this journal will be available via the Ingenta Connect journals service. To view free sample content online visit: www.ingentaconnect.com/content/maney

For further information please contact:

Maney Publishing UK

Tel: +44 (0)113 2497481 Fax: +44 (0)1132486983 Email: subscriptions@maney.co.uk

or

Maney Publishing North America

Tel (toll free): 8662975154 Fax: 6173546875 Email: maney@maneyusa.com

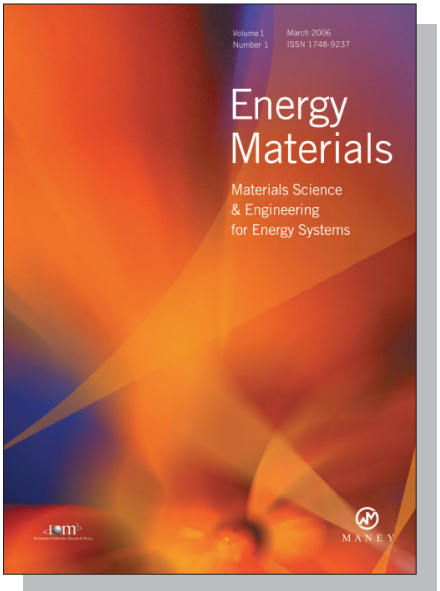

EDITORS

Dr Fujio Abe

NIMS, Japan

Dr John Hald, IPL-MPT, Technical University of Denmark, Denmark

Dr R Viswanathan, EPRI, USA

\section{SUBSCRIPTION INFORMATION}

Volume 1 (2006), 4 issues per year

Print ISSN: 1748-9237 Online ISSN: 1748-9245

Individual rate: $£ 76.00 / U S \$ 141.00$

Institutional rate: $£ 235.00 /$ US $\$ 435.00$

Online-only institutional rate: $£ 199.00 / U S \$ 367.00$

For special $\mathrm{IOM}^{3}$ member rates please email

subscriptions@maney.co.uk

\section{For further information or to subscribe online please visit www.maney.co.uk}



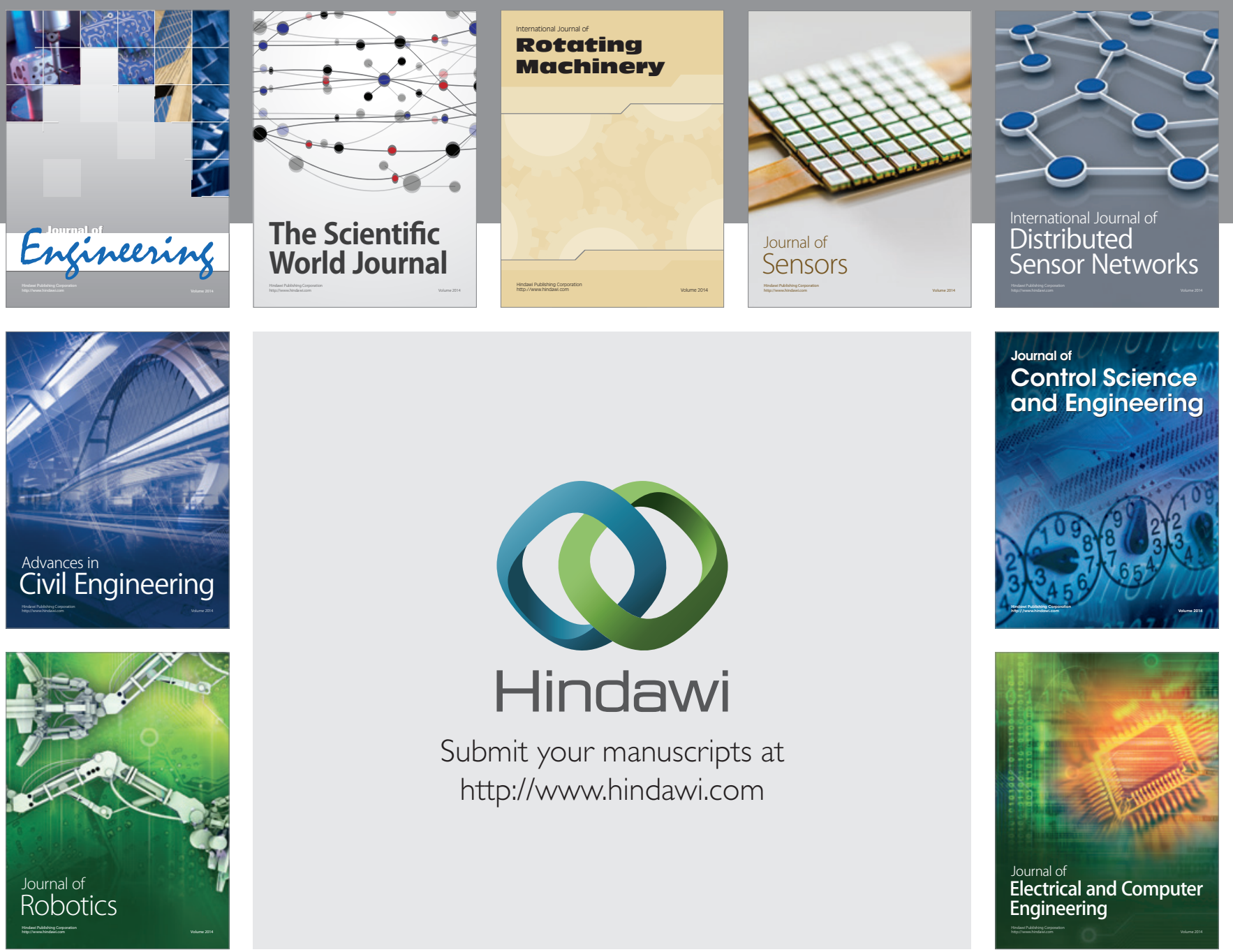

Submit your manuscripts at

http://www.hindawi.com
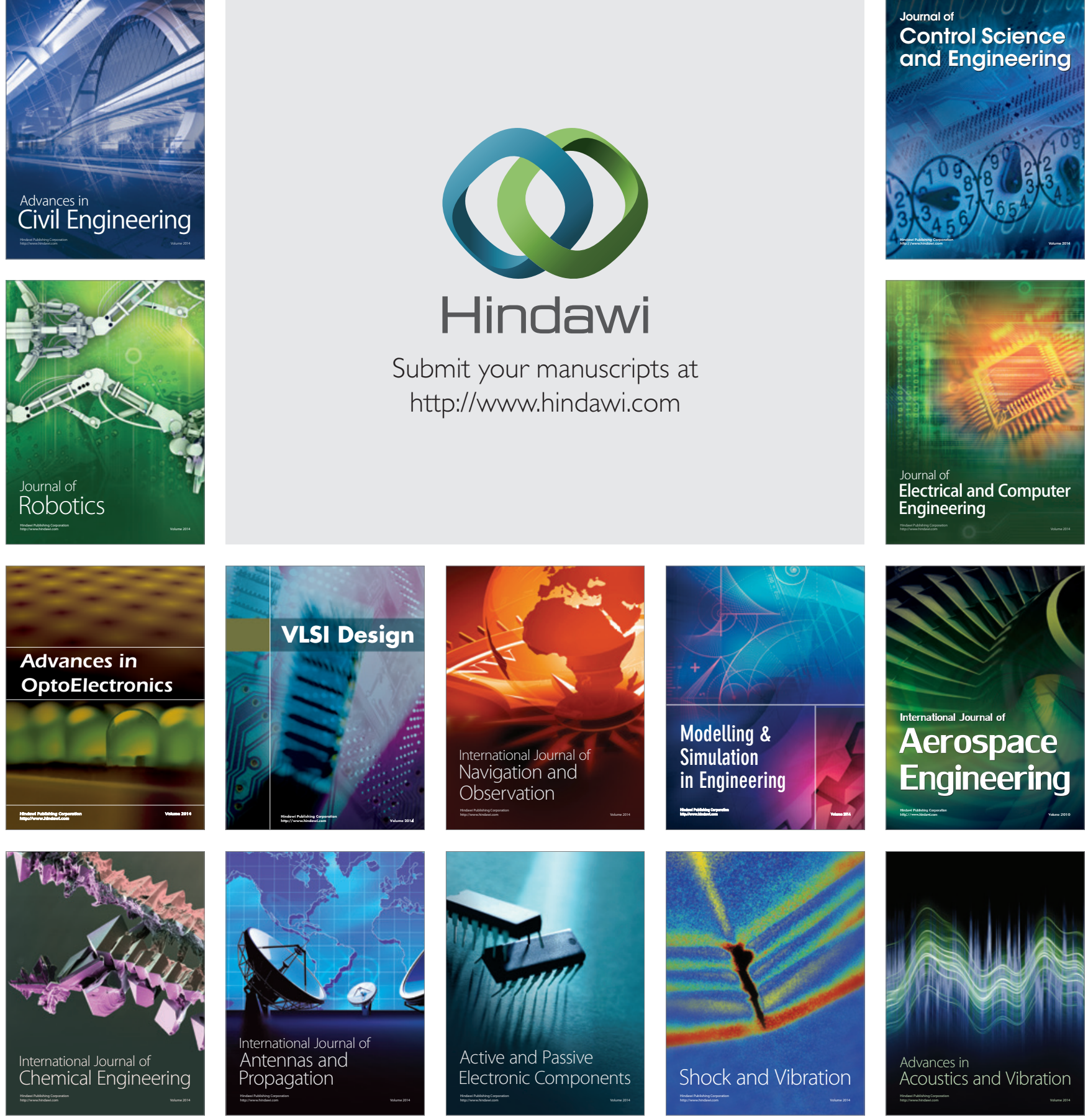